"which are clearly to a demonstration nothing but roots and stomata in all stages of development; $* * *$ but that they" (i.e. the antherozoids) " have tails and whiskers is pure imagination." If Mr. Dawson, nevertheless, or any other gentleman will spend an hour or two with the author of this article, next spring (if spared to see the "green leaves come again"), he will go away without any shadow of doubt about the stirring fact of those masculine appendages to the antherozoidal bodies!

But one word more, as a critic, and that with respect to the doubt expressed by Mr. Dawson, as to whether it be true, as stated by Balfour, Moore, Carpenter, Lindley, and Hofmeister, that germination takes place indifferently from any point of the surface of the spore, and not from fixed points. The writer must confess, and that with great diffidence, in the face (if it be really so) of such high names, that he does somewhat participate in Mr. Dawson's doubts; though he may, very possibly, soon have to retract even this modicum of dissentient opinion. And now his attention is called to the point, he will find, probably, but little difficulty (owing to the abundant means for investigation at his command) in satisfying both himself and friends on this question; his only reason for at all demurring to the opinion of the eminent writers above mentioned, arising from the peculiar forms and ornamentation of certain fern spores, which would seem to bespeak a special relationship and subservancy of parts one to the other, and not an indefinite one as regards germination.

It may be observed, lastly, that whatever ferns may do when left to natural circumstances in their native haunts, they only attain their growth very slowly when propagated on sandstone under bell-glasses. At least, spores of Filix mas and Pteris tremula, for instance, which were sown in the early spring of 1859 , and potted in 1862, only began to exhibit fructification on their fronds in July 1864. On the other hand, whilst probably not one fern-spore in a million (if that proportion, even) germinates when left to nature, nearly every one of them will grow when under the artificial treatment described in the preceding pages. It is, not, however, to be concluded that the countless millions of spores which fail to germinate do not fulfil some more or less important part in the hidden economy of Nature. 


\section{A BRIEE HISTORY OF A RIVER TANK.}

\section{BY SHIRLEY HIBBERD.}

An object with which most of my friends are familiar is a plain rectangular tank, containing rockwork, water, and gold fishes, and which occupies a conspicuous place in the entrancehall of my residence at Stoke Newington. It is such a very unpretending affair that I dare say many of my friends will at this stage of my "brief history" think that I have made a mistake in selecting such a subject for a paper in the INTELLECT'UAL Observer, but if they will just read on, I have no doubt I shall be able to satisfy them that my tank is an object of some interest, not only to myself personally, but to the cultivators of aquaria everywhere. In the Book of the Aquarium I have endeavoured to expound the "natural system" of tank management, which, as its name implies, is the only system by which satisfactory results of a permanent nature are to be obtained. The history of aquaria in the most extensive sense, is simply a history of the rival pretensions and diverse results of the artificial and natural systems of management. The artificial system is, perhaps, no system at all, because the practitioner seeks merely to gratify his fancy in forming an assemblage of aquatic plants and animals; the tanks are elaborately decorated with fountains, grottoes, and banners of vegetation, and stocked with crowds of fish.

Under some circumstances the artificial system answers admirably; in others it is a failure from the first, and every repetition of the experiment ends in the same disappointment. For all show purposes the artificial system is invaluable. It has often been my lot to exhibit tanks at soirées, converzaziones, etc., and they have always been greatly admired; but so thoroughly artificial have been the arrangements that I have sometimes taken up from the garden tufts of Holcus saccharatus, Arundo donax, and other large plants of graceful habit, and, having washed the earth from their roots, have planted (i.e. fixed) them in good positions, pro tem., for crowds of gold fishes, minnows, bleak, etc., to gambol amongst. I remember some years ago, when visiting Leeds to deliver some lectures on aquaria, I had the privilege of inspecting the tanks of Dr. Hobson, which were the most satisfactory exemplifications of artificial management $I$ had then or have since seen. A very elegant room was appropriated to a series of vessels, in which was kept up a constant and copious run of water, the stream passing from tank to tank, the tanks being in a succession of levels, so that from one end of the room 
all were visible in an ascending series, which produced an agreeable tout ensemble, and at the same time made one source of water supply sufficient for the whole. This was a strictly artificial arrangement, but it was perfectly successful. The tanks were all well stocked with fishes, reptiles, insects, etc., classified according to their habits and proclivities, and so grouped that when viewed collectively, the scene was beautiful in the extreme. One more instance of artificial management for show purposes will, perhaps, suffice. When lecturing at the Reading Institution some years ago, Ihad an accident, and spoiled nearly all the sea-water that had been secured for the display. But I was not to be beaten by trifles. I had enough sea-water left to fill a few large shallow glass pans; into these pans I transferred the anemones, star-fishes, etc., and gave them just enough water to cover them, and in the show tanks I grouped the large handsome specimens of alga that had been collected for the purpose, so as, with serpulæ shells, rocks, etc., etc., to make handsome groups, and filled those tanks with water drawn from the Institutional water-butt, and kept the secret to myself from that day to this. That was a perfectly successful undertaking; the tanks looked beautiful by gaslight, with their grand groups of algre, and as for the animals, the thin film of water over them, and their recent travel and subsequent transference from their places in the tanks, caused just enough of that peculiar irritation which seems to be needful to cause a full display of the beauties of certain of the Radiates, and the audience had the advantage of beholding star-fishes, plumose anemones, and other marine subjects, in the attitudes they habitually assume when safely anchored fathom deep in ocean brine.

The natural system is an imitation of nature, not in outward appearances merely, but in conditions. Tanks managed on the natural system may be made to have a most beautiful appearance, and I flatter myself that the example I am now to bring before you could not be easily surpassed for beauty, considering it simply as an appropriate item in a "home of taste." But it is impossible to use such vessels for show purposes; any disturbance of the furniture would be a violation of the most essential conditions, and mere decorations are not to be tolerated; they are, in fact, forbidden by the laws on which the system is based. How do we proceed to carry out the natural system? We form within a vessel or vessels a group or groups of objects in imitation of rock-pools, running streams, lakes, ponds, and so forth. If it is intended to keep in any of the vessels creatures that habitually dwell in mud, there must be a bottom of mud for them. If retiring places and dark recesses are needed, they must be built; whatever is to be the 
purpose of any particular vessel, it must be prepared in the first instance so as to contain within itself all the conditions essential to success, and when it is completely stocked it must be left to take care of itself; and if it becomes unsightly, or the animals become diseased and perish, then in that particular instance the natural system has failed through some error or oversight of the practitioner. Of course in all this there is much that is artificial; for instance, it is artificial to put fishes into glass vessels of any kind, and very artificial to build miniature caves and grottoes of coke or broken bricks; but the term natural system is nevertheless quite legitimate, because the endeavour at every step is to illustrate the operation of natural laws; whereas on the other system the endeavour may be simply to carry out a fanciful device, or a scheme which in its first elements sets the laws of nature at defiance.

The tank I have to describe was fitted and furnished more than seven years since. It is a simple rectangular vessel, in form nearly a double cube, and its position is in the entrancehall adjoining the rear wall, where it is sufficiently illuminated to render every part of its contents agreeably visible to the eye, yet it receives scarcely any direct light whatever. It is impossible there should be anything more simple than the furnishing of this vessel, yet it does not lack certain features that render it attractive to unscientific eyes. I fitted it myself, and proceeded as follows:-I procured from the cellar a number of large pieces of coke, some of which were broken, to afford ample choice of blocks of various forms and sizes. Those were preferred which had a somewhat rugged face, but which nevertheless were large and flat, giving plenty of linear surface, so as to be best adapted for building a wall of very moderate thickness. These were two or three times dipped into a thick batter of Portland cement, and were finally cemented together in blocks of suitable width for convenient lifting, with one or two empty flower pots at the base and within every block. The flower pots were used to create a flat basis, so that each block would rest on the bottom of the tank securely, and for the additional reason of the increased lightness of the blocks so constructed, the fronts being made solid and massive, yet hollow within, and the pots not at all or only slightly covered with rock on the sides intended to form the backs of the blocks. Thus a rugged wall of rock was formed in a series of detached pieces, massive in appearance, yet of no greater weight than admitted of convenient lifting. Such a wall made of mica schist-which is the best of rocks for aquaria where its weight is of no consequence-would soon have ruined the tank, and perhaps have brought down tank and stand within a few hours of the first fitting. With coke and flower- 
pots you may build another Tower of Babel, and its weight would scarcely make an indentation on a newly-ploughed field.

The rocks were, as soon as tolerably hard, placed in a large vessel of water. A tank in the garden used for ordinary garden purposes, answered admirably for the soaking process that all newly-cemented work must undergo before it should be used in an aquarium. The only preparation the tank itself underwent was to colour the back, so that glimpses of the wall should not be seen through any possible interstices of the rockwork. I took some sheets of green tissue paper, smeared the back plate of the glass all over with copal varnish,

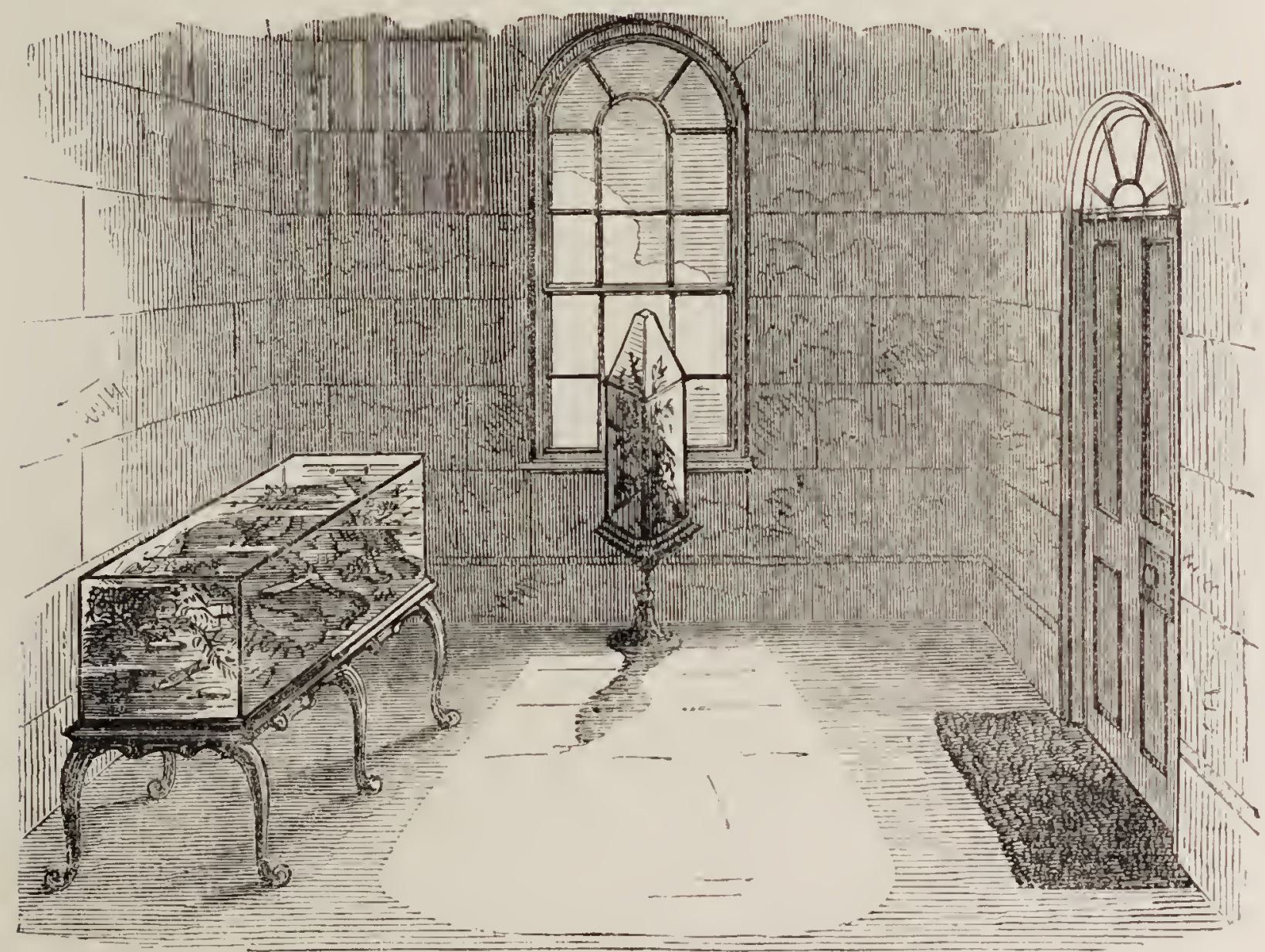

pressed the paper smooth on it, and by that experiment determined that if it ever becomes needful to colour one side of a tank, the paper and varnish is the most effectual and cleanly that can be adopted. In due time-a fortnight perhaps, not less-the blocks were taken from the bath and placed in position. A bottom of clean well-washed pebbles was laid down, the tank was then filled with water, and the gold fishes and minnows were introduced.

That is nearly all that has been done to the tank from that day to this. Yet a few things remain to be said. In the first place, it has been a complete success, and the nature of that 
success may, perhaps, surprise some of our non-successful aquarians. For instance, the water has never once, during a period of over seven years, been pea-soupy, or even cloudy, or otherwise than as brilliant as all that we have in our mind's eye when talking of the "crystal spring" and the beverage of Castally. There have been deaths in it-deaths by"compulsion, the result solely of experiments made with a view to test the extreme capabilities of the system; but there are in the tank at this time gold fishes that I have had in my keeping, and that have never been otherwise than healthy and happy, during a period of more than nine years. If any of our reader's have kept gold fishes in glass vessels as long or longer than I have, I should much like to hear of it, and with the fact a word as to the conditions. Furthermore, to keep this tank in order is a matter of such small trouble that it may be literally said to take care of itself. Ordinary dusting and occasional cleansing of the exterior are, of course, necessary, and for the interior there are two operations only that are needful. The fishes are fed with rice boiled in water, or with bread crumbs. I believe that bread is as good a food as they can have, and as it is always handy, it is a great advantage to be able thus simply to perform a duty which is generally too much neglected, for there are still to be found some benighted people who think that gold fishes can live on the invisible tenants of the tank, and get fat, as it were, upon nothing. The other operation is the occasional cleansing of the front plate inside. This is accomplished by means of a piece of sponge, attached, by means of twine, to the end of a stick, and the stick is thrust behind the tank, so as to be always handy for the purpose. This cleansing of the front plate is performed about once a fortnight during summer, and not more than once in three months during winter; in fact, it might be left undone from November to March, and the view would be unimpaired by even the slightest film of confervæ; but from March to October the growth is sufficiently rapid to produce a perceptible green tinge on the glass in eight or ten days, and this is easily removed by the sponge. In cases of long neglect I find the most effectual mode of cleansing to be with a cloth on which a little silver sand is sprinkled; this, drawn over the glass with the sand, brings away the crust at once, and if carefully done, appears not to cause any serious scratching of the glass, though if the glass were of poor quality, perhaps it might.

The reader has of course taken note of the omission from this history of all mention of the introduction of plants to the tank. I have never introduced a plant of any kind, yet the rocky wall is richly coloured with microscopic forms of vegetation in beautiful green, bronze, and russet patches, and if the 
glass ends are left untouched, they in time become quite opaque with a dense coating of olive-coloured vegetation. This is one of the grand features of the natural system. I may introduce a thousand plants, Anacharis, Valisneria, Stratiotes, etc., etc., and they may all perish. But those Dame Nature introduces are sure to live. Being developed in situ they are of constitutions adapted to the conditions which exist in the tank, and though it requires a long time for a ressel, situated as this $i s$, to become richly clothed with suitable oxygen makers, some supply of oxygen is secured from the very first, for I lave seen ciliated spores and beginnings of genuine vegetable deposits within a few hours of the first furnishing of a tank. Hence it was that, fortified by previous experiences of the matural system, I did not hesitate to introduce the fishes as soon as the tank was furnished, without waiting for the full development of the microscopic forest, for I knew that before the fishes exhausted the oxygen in the fresh river water, there would be the beginning of a new supply for them, and there was never any distress through that procedure.

I have italicised above the words "situated as this is." The situation of this tank is the secret of its success. Near it on one side is a window facing west. This window lights the hall abundantly, but very few rays of light from it fall directly on the tank. The only direct light which strikes upon the tank comes from the fanlight over the door directly opposite, and that is, of course, but moderate in amount. Now, in the early days, when I wanted a quick growth of Oscillatoria, and other oxygen makers, I had the blind drawn up at the side window, and there was then no fern case there. The abundance of light caused a speedy diffusion and germination of spores, and as soon as I saw that the vegetation was likely to be too plentiful, I had the blind drawn down, and intercepted the light that still came by means of a fern case. Thus by toning down the daylight, and having my tank where an excess of light was impossible, I secured a moderate, yet plentiful grow th of plants, and have never had one vegetable filament more than needful, except on the front glass, where of course it intercepts the view of the interior. It must not be supposed, however, that the hall is dark in consequence, it is, in fact, well lighted, and very cheerful.

Now a word for the fishes. I find that for a vessel of this sort, which though to me an experimental and scientific affair, is in all other respects a piece of elegant furniture, there are no fishes that may be kept with such certainty as gold carp. My old friends of nine years' standing (or swimming) have gone through several severe trials and seem none the worse. I cannot say how much they have grown during 
this long period; but I think they have grown, though certainly very little. They are tame and lazy, and happy and beautiful, and they have served an important purpose to me besides the adornment of the hall, for, after their seven years' habitation of this tank, having had two years of active experimentalizing previously, they have solved the problem of the cubic space required by a fish for breathing room, and I shall be able to give a safe rule for the guidance of all cultivators of aquaria. I have arrived at the maximum capacity of my tank in various ways. One way was to introduce occasionally a few new fishes. As common carp abound in a pond close by, a good many have had temporary residence in the tank. Minnows have been used in the same way, and I have also added gold carp, and other fishes which are generally tolerably adaptable in constitution. But it always happened that when the fishes exceeded a certain number there were signs of distress. I could not begin changing the water to obviate this, because that would be to annihilate the natural system "at one fell swoop." No, the water has never been changed during the whole seven years, though, of course, it is necessary occasionally to make good the loss by evaporation. But I did try on a few occasions of extreme distress to aërate the water by the use of a garden syringe. Charging this from the tank the water was ejected back with force through some slight atmospheric distance, carrying streams of bubbles to the bottom of the vessel. This would be amusing, because the fishes would rush at the streams of bubbles and absolutely gulp them; but it was fagging work, and, of course, was only performed by impulse and not by system. The end of every one of these experiments was the same. One or two of the newly introduced fishes would, after the lapse of about a fortnight, be found dead and "floating on its watery bier." Next a few more would die, and so on till the whole of the new comers were cleared off, and the old, well-seasoned members of the "happy family" remained unhurt, but breathing more freely for the relief, and no doubt rejoicing to have got rid of the innovators. Suppose now that you have some gold fishes, averaging four to six inches in length, to preserve for any length of time by the natural system, and under circumstances at all resembling the case here described, for half-a-dozen of those fishes you must have a vessel holding at least twenty-four gallons of water. The smallest of your fishes will need three gallons, all larger four or five gallons. Most of the failures in tank management have resulted from over-stocking, but the modification of the light is an equally important matter.

The natural system can be carried out in marine tanks in much the same manner as in river tanks, though, of course, 